\title{
Special Issue of Papers by Plenary and Topical Invited Lecturers at 21st International Symposium on Plasma Chemistry (ISPC 21), 4-9 August 2013, Cairns, Australia: Introduction
}

\author{
Anthony B. Murphy
}

Published online: 2 April 2014

(C) Springer Science+Business Media New York 2014

I am delighted to present this Special Issue, which contains papers by plenary and topical invited lecturers of the 21st International Symposium on Plasma Chemistry (ISPC 21), which was held at Cairns Convention Centre, Cairns, Queensland, Australia, from 4 to 9 August 2013. ISPC is a biennial international conference, whose governing body is the International Plasma Chemistry Society. The topics covered by the conference span the full range of plasma chemistry and plasma processing research, from fundamentals to applications, and including low-pressure, atmospheric-pressure non-equilibrium and thermal plasmas.

21st International Symposium on Plasma Chemistry was chaired by Professor Rod Boswell of Australian National University and Dr Tony Murphy of CSIRO Materials Science and Engineering. The conference was sponsored by CSIRO, BOC Australia (a member of the Linde Group), LAM Research, Australian National University, Oregon Physics, Journal of Physics D: Applied Physics, American Elements, Wiley VCH, and the Mawson Institute of the University of South Australia, and was organised by Ozaccom+ Conference Services.

A total of 295 participants from 24 countries, including 85 students, attended ISPC 21. Six plenary and twelve topical invited lectures were presented, in addition to 127 contributed oral presentations and 188 contributed poster presentations. The conference proceedings are available at the International Plasma Chemistry Society website (www.ispcconference.org).

At the conference, the Plasma Chemistry Award, the highest award of the International Plasma Chemistry Society, was presented to Professor Michael Wertheimer of École Polytechnique of Montreal.

For this Special Issue, all plenary and invited lecturers, in addition to eight researchers who were asked to present topical invited lectures but were unable to attend, were invited to submit papers. All papers submitted underwent the full refereeing procedure of Plasma Chemistry and Plasma Processing.

\footnotetext{
A. B. Murphy $(\bowtie)$

CSIRO Materials Science and Engineering, PO Box 218, Lindfield, NSW 2070, Australia

e-mail: tony.murphy@csiro.au
} 
A total of 18 papers were accepted for publication, and are presented in this issue. They comprise papers from four plenary lecturers (Rikizo Hatakeyama, Michael Kong, Takayuki Watanabe and Michael Wertheimer), nine topical invited lecturers (Eun Ha Choi, Fiorenza Fanelli, Steven Girshick, Jean-Luc Meunier, Tatsuru Shirafuji, Holger Vach, Krasimir Vasilev, Hai-Xing Wang and Keping Yan), and five researchers who were asked to present topical invited lectures but were unable to attend (Peter Bruggeman, Jörg Friedrich, Amnon Fruchtman, Claus-Peter Klages and Irina Schweigert), and their co-authors.

The strong response ensured that the all the main topic areas of the conference are represented in the Special Issue, providing an excellent record of the state-of-the-art in plasma chemistry and plasma processing research, presented by leaders in the field. 